\title{
BILÍNGUES E BILINGUISMOS: UMA TAREFA DE LEITURA E COMPREENSÃO DE TEXTO COMO ALTERNATIVA DE AFERIC̣ÃO DE PROFICIÊNCIA LINGUÍSTICA E FLUÊNCIA ORAL GLOBAL EM LÍNGUA INGLESA
}

\author{
BILINGUALS AND BILINGUALISMS: A READING COMPREHENSION TASK AS AN \\ ALTERNATIVE TO MEASURE LINGUISTIC PROFICIENCY AND GLOBAL FLUENCY \\ IN ENGLISH AS L2
}

\author{
Joelton Duarte de Santana ${ }^{29}$ \\ Janaina Weissheimer ${ }^{30}$
}

\begin{abstract}
RESUMO: Ao presente artigo interessou analisar como uma tarefa de leitura e compreensão de texto (ANEMA, 2008), pode ser considerada como critério de proficiência linguística (SEGALOWITZ, 2010; TAVAKOLI, 2011), em experimentos envolvendo sujeitos bilíngues. A literatura tem sugerido que a grande maioria dos testes empregados para aferir proficiência linguística de sujeitos bilíngues, assim o é, a partir de critérios e parâmetros monolíngues, sobretudo aqueles que priorizam e enfatizam aspectos estritamente gramaticais. Nesta feita, após aplicar o teste de proficiência VLT (Vocabulary Level Test), nos moldes de Nation (1990), com sujeitos bilíngues brasileiros, comparamos o desempenho obtido pelos sujeitos investigados com um método alternativo de leitura e compreensão de textos. Após análise de dados, foi possivel perceber que o número de palavras lidas e o tempo de leitura podem se instituir, igualmente, estratégia válida para aferição de proficiência linguística em língua, uma vez que não houve diferença significativa entre os desempenhos apresentados em ambos os testes, VLT e Teste de Leitura, pelos sujeitos bilíngues brasileiros investigados, quando agrupados nos níveis básico, intermediário e avançado, se comparados aos seus pares, bilíngues nativos, bilíngues tardios e nativos monolíngues, recrutados no exterior. $\mathrm{O}$ presente artigo reforça a necessidade de, em estudos envolvendo bilíngues e bilinguismos, considerá-los como seres holísticos e multicompetentes (GROSJEAN, 2010; 2013; COOK, 2016).
\end{abstract}

Palavras-chaves: Proficiência linguística; língua inglesa; bilíngues e bilinguismo.

\begin{abstract}
In the present article, we analyze how a reading and comprehension task (ANEMA, 2008) can be considered as a criterion of language proficiency (SEGALOWITZ, 2010; TAVAKOLI, 2011), in experiments involving bilingual subjects. The literature has suggested that the vast majority of the tests used to gauge bilingual subjects' language proficiency are based on monolingual criteria and parameters, especially those that prioritize and emphasize strictly grammatical aspects. In our study, after applying the VLT (Vocabulary Level Test), proposed by Nation (1990), with Brazilian bilingual subjects, we compared the performance obtained with this test to an alternative method of reading and comprehension. Results show that the number of words read and the reading time are also a valid strategy for measuring language proficiency, since there was no significant difference between the performances presented in both tests, VLT and Reading Test, by the Brazilian bilingual subjects investigated, when grouped by basic, intermediate and advanced levels, compared to their counterparts: native bilingual, late bilingual and monolingual native speakers. This article reinforces the need to consider bilingual subjects as holistic and multicompetent beings (GROSJEAN, 2010; 2013; COOK, 2016).
\end{abstract}

Keywords: Linguistic proficiency; English as a second language; bilinguals and bilingualism.

\footnotetext{
${ }^{29}$ Doutor em Linguística - Aquisição de Linguagem e Processamento Linguístico - pelo Programa de Pós-Graduação em Linguística (PROLING) da Universidade Federal da Paraíba - UFPB, com estágio doutoral (doutorado sanduíche) realizado na City University of New York - CUNY - Queens College em Nova Iorque (EUA). Professor Adjunto da Universidade de Pernambuco- UPE - Campus Mata Norte. Professor Colaborador do Programa de Pós-Graduação em Estudos da Linguagem (PPgEL) da Universidade Federal do Rio Grande do Norte-UFRN.

${ }^{30}$ Doutora em Letras (Inglês e Literatura Correspondente) pela Universidade Federal de Santa Catarina-UFSC. Realizou estágio pós-doutoral (bolsista CAPES) no Kutas Cognitive Electrophysiology Lab na University of California San DiegoUCSD. É professora associada do Departamento de Línguas e Literaturas Estrangeiras Modernas da Universidade Federal do Rio Grande do Norte-UFRN em Natal, membro permanente do Programa de Pós-Graduação em Estudos da Linguagem-PPGEL-UFRN e colaboradora no Instituto do Cérebro da UFRN.
} 


\section{Introdução}

Estudos sobre o bilinguismo têm proposto que os sistemas linguísticos presentes na mente de um bilíngue não funcionariam separadamente (GROSJEAN, 2010; 2013; COOK, 1997; 2016). Tais estudos têm dispensado esforços na proposição de modelos relacionados à maneira de como duas ou mais línguas são representadas, ativadas e inter-relacionadas na mente de um indivíduo.

Segundo Cook (1997), muitos dos questionamentos sobre o bilinguismo dizem respeito à relação existente entre os dois sistemas linguísticos presentes em uma mesma mente e se tais línguas formariam dois sistemas separados durante rotinas de leitura, compreensão e processamento em uma dessas línguas ou se formariam um sistema único combinado. Embora seja um fato característico do bilinguismo que o falante bilíngue saiba duas ou mais línguas, a forma que essas línguas são organizadas na mente desse falante, segundo Hsin et al (2013), está longe de ser autoevidente.

No entanto, no que diz respeito à seleção de população e amostra envolvendo sujeitos bilíngues, por exemplo, testes que visam a aferir sua proficiência em uma de suas línguas têm, na grande maioria das vezes, obedecido padrões e critérios monolíngues, além de priorizar um conhecimento metalinguístico explícito (DE DIEGO BALAGUER et al., 2005; CHEE, TAN, \& THIEL, 1999; PERANI et al., 1998, PERANI et al., 2003).

Interessa-nos, portanto, saber, se tarefas e testes de leitura e compreensão orais, por exemplo, que visem a aferir proficiência de sujeitos bilíngues, instituem-se estratégias e instrumentos válidos para ratificar achados de fenômenos que envolvam sujeitos bilíngues e que estejam relacionados direta ou indiretamente a sua proficiência em uma de suas línguas.

Para que o presente estudo seja possível, propusemo-nos a analisar e descrever em que medida um teste de leitura e compreensão de texto em língua inglesa (ANEMA, 2008), envolvendo aferição do tempo de leitura e número de palavras lidas por minuto, pode ser empregado como teste de proficiência em língua inglesa envolvendo sujeito bilíngues, assim como testes envolvendo níveis e extensão de vocabulário, a exemplo do Vocabulary Level Test (NATION, 1990), têm sido.

A discussão apresentada neste artigo foi organizada em três seções, que se somam às de Introdução, Considerações Finais e Referências Bibliográficas.

Na seção intitulada: "Descrevendo o Bilinguismo e Falantes Bilingues", descrevemos o bilinguismo enquanto estado de uso de, no mínimo, duas línguas, à medida que apresentamos as classificações mais relevantes e atuais para estudos que envolvam sujeitos bilíngues e seus bilinguismos.

Em seguida, na seção cujo título é: "Relação entre Fluência e Proficiência: Tempo de Leitura", aventamos sobre a possibilidade de assumir que a proficiência linguística e a fluência oral global possam ser definidas e descritas a partir de critérios como precisão de palavras lidas e tempo de leitura.

Por fim, intitulada "Aspectos Metodológicos e Experimentais, descrevemos os aspectos metodológicos do experimento proposto, sua configuração experimental e perfil dos sujeitos participantes deste estudo, os quais foram recrutados no Brasil (João Pessoa, Paraíba) e no exterior (Nova Iorque, Estados Unidos), sendo classificados e agrupados conforme proficiência e contexto de bilinguismo no qual estavam inseridos.

Após análise e discussão do fenômeno proposto, percebemos que estudos envolvendo sujeitos bilíngues, bilinguismos e potenciais modelos e instrumentos de aferimento e confrontação de proficiência linguística e proficiência oral global devem, cada vez mais, e, sobretudo, considerar contextos linguísticos e culturais individuais, a exemplo de cada tipo de realidade bilíngue e dos falantes bilíngues a ela associados. 


\section{Descrevendo o Bilinguismo e Falantes Bilíngues}

O bilinguismo tem sido cercado por inúmeros mitos, a exemplo de que, os bilíngues são raros e têm perfeito conhecimento de suas línguas; bilíngues reais adquiriram suas duas ou mais línguas durante a infância e que não teriam sotaque algum em nenhuma de suas línguas; bilíngues são tradutores natos; a mudança entre as duas línguas seria um indício de preguiça nos bilíngues; todos os bilíngues seriam também biculturais; bilíngues teriam dupla ou, pelo menos, personalidades divididas; o bilinguismo atrasaria a aquisição da linguagem em crianças e teria efeitos negativos em seu desenvolvimento. ${ }^{31}$

Tais mitos cercaram, por muitas décadas, os estudos envolvendo sujeitos bilíngues, sobretudo àqueles envolvendo critérios de classificação e aferição de seus "bilinguismos". Em virtude disto, muitos bilíngues não se consideram como tais, sendo extremamente críticos em relação a sua própria competência em uma de suas línguas, mais notadamente sua segunda.

Assim, acreditamos que a pessoa bilíngue não deva ser considerada como dois monolíngues separados. Para Grosjean (2010), pessoas bilíngues são aquelas que usam duas ou mais línguas em suas vidas diárias. $\mathrm{O}$ autor afirma, inclusive, que o bilinguismo é, de fato, presente praticamente em cada um dos países no mundo, em todas as classes da sociedade e em todos os grupos etários.

Bilíngues adaptariam sua produção linguística à situação e àqueles com os quais interagem, sejam monolíngues ou bilíngues. Isso porque, segundo Grosjean (2008), bilíngues geralmente adquirem e usam suas línguas para diferentes propósitos, em diferentes domínios de suas vidas e com pessoas diferentes.

Assim sendo, em se tratando de estudos envolvendo bilíngues, qual seria, então, a melhor maneira de atestar seu conhecimento em uma de suas línguas ou em ambas?

Grosjean (2008, p.34) sugere o bilinguismo como sendo o uso regular de duas ou mais línguas (dialetos) e falantes bilíngues como aquelas pessoas que usam duas ou mais línguas em suas vidas diárias. Nesta feita, recorremos a visão bilíngue ou holística do bilinguismo, conforme proposto por Grosjean $(2008$, p. 36) que propõe que o falante bilíngue é um todo integrado e que não pode ser decomposto em partes, como resultantes de dois monolíngues completos ou incompletos.

Assim, conduzir testes de proficiência que priorizem, única e exclusivamente, vocabulário ou conhecimento gramatical (metalinguístico) explícito incorreria na tentativa de decompor o sujeito bilíngue e avaliá-lo através de moldes monolíngues.

No entanto, embora o bilinguismo, enquanto estado de uso de, no mínimo, duas línguas, tenha sido discutido e proposto como norma, pelo menos na grande maioria dos países do mundo, não há consenso unânime acerca da definição do indivíduo bilíngue. Segundo Beardsmore (1986), o bilinguismo, preferivelmente, deveria ser assumido como um continuum, e, ao longo desse continuum, existiriam pessoas que apresentariam maior ou menor "grau de bilinguismo".

Diversas são as tentativas de classificar os falantes bilíngues baseando-se em seu grau de proficiência e competência nas línguas faladas, em sua idade, contexto de aquisição e até pelos mecanismos de processamento de representação de ambas as línguas. Uma concepção equivocada que persistiu ao longo dos anos foi a de que o bilíngue domina, ou deveria dominar, fluentemente as duas línguas que fala.

A literatura tem proposto várias definições com o intuito de dar conta das diferenças dos perfis dos falantes bilíngues e de suas habilidades nas línguas faladas. Termos como bilíngues, bilíngues nativos ou de nascença (early bilinguals), bilíngues tardios (late bilinguals), bilíngues

\footnotetext{
${ }^{31}$ Para maiores detalhes sobre tais mitos conferir Grosjean (2010).
} 
balanceados (balanced bilinguals), bilíngues receptivos ou passivos (receptive bilinguals) têm sido largamente utilizados ao longo das décadas na iniciativa de entender a mente bilíngue e precisar as habilidades linguísticas e o perfil de história das línguas faladas.

Mesmo em meio a falta de consenso, as classificações mencionadas ainda continuam a ser utilizadas e têm ocorrido majoritariamente, em termos de idade e das habilidades linguísticas do indivíduo bilíngue.

No que diz respeito a idade do bilíngue ou mais precisamente a idade em que suas línguas foram adquiridas, por exemplo, psicolinguistas têm classificado os falantes bilíngues como bilíngues nativos (ou de nascença) ou bilíngues tardios (BEARDSMORE, 1986; SWAIN, 1972). Os bilíngues de nascença, ainda, podem ser classificados como bilíngues simultâneos, quando ambas as línguas são adquiridas simultaneamente desde o nascimento; ou como bilíngues sequenciais, quando a segunda língua é adquirida após a primeira língua já ter sido, pelo menos parcialmente, adquirida. Ambas as línguas, nesse sentido, seriam adquiridas ainda na primeira infância. Os bilíngues tardios, em comparação àqueles, são considerados os falantes que adquiriram a língua após a primeira infância, especialmente na adolescência ou na vida adulta.

No que diz respeito às habilidades dos bilíngues nas línguas por eles faladas, as classificações mais largamente adotadas são as de bilíngues dominantes, bilíngues balanceados, equilíngues e bilíngues passivos. Os bilíngues dominantes consistiriam naqueles falantes que são mais proficientes em uma das línguas faladas e que apresentariam proficiência semelhante a de falantes nativos. Sob o impacto de uma língua dominante e a relação entre a dominância de uma ou outra língua de um bilíngue e o tempo, Grosjean (2008, p.33) afirma que a competência que os bilíngues apresentam em uma de suas línguas pode mudar, ainda que moderadamente.

Os bilíngues balanceados, de acordo com Peal e Lambert (1962), seriam os bilíngues que são igualmente proficientes em ambas as línguas faladas, na maioria dos casos, apresentando proficiência semelhante ou idêntica aos falantes nativos.

Os bilíngues passivos, ou receptivos, seriam aqueles considerados falantes nativos em uma das línguas, necessariamente na L1, com capacidade apenas de entender, mas não de falar na segunda língua. Sobre o bilinguismo receptivo, Grosjean (2010, p.236) reforça que o falante bilíngue consegue entender em uma língua, mas não consegue escrever, ler ou até falar, por exemplo.

Por fim, os equilíngues seriam os bilíngues capazes de se passar em qualquer situação comunicativa como um falante nativo, sendo necessariamente indistinguíveis desses últimos. No entanto, essa seria a visão mais restrita e, consequentemente, mais radical sobre o bilinguismo. Embora considerada teoricamente ideal (WEINREICH, 1953), tal noção seria notadamente rara na prática, segundo propõe Lyons (1981).

Tais definições apresentadas sobre bilinguismo a partir da multiplicidade e variedade de sujeitos bilíngues, tornam-se necessárias, uma vez que aferir os níveis de bilinguismo e proficiência linguística em uma de suas línguas (ou em ambas) não parece ser tão autoevidente como alguns estudiosos tendem a sugerir.

Isto porque, segundo Nichols (2013), nem todos os estudos envolvendo aquisição e aprendizagem de L2, ou ainda a comparação entre sujeitos monolíngues e bilíngues, por exemplo, têm empregado medidas objetivas de proficiência. Na maioria das vezes estudiosos têm optado por medidas de autoavaliação de proficiência por parte dos participantes (DE DIEGO BALAGUER et al., 2005); outros têm utilizado séries ou módulos de curso de idiomas (CHEE, TAN, \& THIEL, 1999) e outros ainda têm se valido de desempenhos apresentados em tarefas de tradução de textos (PERANI et al., 1998, PERANI et al., 2003) como medidas de proficiência.

Em contrapartida, o presente estudo busca validar uma tarefa de leitura e compreensão de texto, a partir da contagem de número de palavras e tempo de leitura, comparando-o com o desempenho igualmente obtido a partir do Vocabulary Level Test (NATION, 1990) que tem sido 
utilizado em estudos sobre o bilinguismo enquanto teste padronizado de proficiência (SOUZA e SOARES-SILVA, 2015).

\section{Relação entre Fluência e Proficiência: Tempo de Leitura}

O termo "fluência de leitura" refere-se à leitura silenciosa que, por sua vez, está associada à velocidade de reconhecimento de palavras. A leitura oral, segundo Anema (2008), não era considerada um aspecto importante durante processo de leitura. No entanto, segundo a autora, essa realidade acabou mudando quando um relatório do Painel Nacional Americano de Leitura (2000) foi capaz de delinear uma relação entre a fluência da leitura oral e a compreensão leitora em crianças da pré-escola até a idade dos 12 anos.

Para Anema (2008, p.16), três dimensões de fluência podem ser observadas mediante a fluência de leitura, a saber, precisão, velocidade e prosódia. Tanto na leitura oral como na leitura silenciosa, a fluência, para a autora, estaria positivamente correlacionada com a compreensão leitora, posto o fato de níveis avançados de fluência estarem relacionados a uma compreensão leitora precisa e acurada.

Segundo Grabe (1991), a leitura fluente deve ser rápida de modo que o leitor consiga manter a fluidez de informação em um ritmo adequado que o habilite estabelecer conexões e inferências necessárias à compreensão.

Assim, Anema (2008) propõe que os três componentes de fluência, conforme supracitados, e da compreensão, poderiam ser ilustrados a partir da leitura oral observada em leitores iniciantes. Nas palavras da autora, quando leitores iniciantes são instruídos a ler alto, eles tendem a ler palavra por palavra, na maioria das vezes repetindo ou pulando palavras. Nesse sentido, os recursos atencionais estariam esgotados para decodificar as palavras individualmente. Os leitores iniciantes apresentariam, portanto, falta de automaticidade e de precisão durante o reconhecimento de palavras, se comparados a leitores fluentes.

O segundo componente da fluência, segundo Anema (2008, p.16), seria o tempo de leitura, que em leitores iniciantes resultaria em uma notável lentidão enquanto uma possível ineficiência de decodificar, resultando, necessariamente, em pausas frequentes. Em virtude de um ritmo lento de leitura, acredita-se que conexões não seriam estabelecidas entre as palavras lidas devido à sobrecarga na memória de trabalho, logo, reforça a autora, traços de memória desapareceriam antes mesmo da informação ter sido processada.

Em relação ao terceiro aspecto da fluência, que seria a prosódia, leitura com expressão ou até mesmo leitura prosódica, Anema (2008, p.17) sugere que leitores iniciantes frequentemente são considerados inaptos a adicionar ritmo expressivo apropriado e padrões melódicos a sua leitura, uma vez que sua atenção estaria focada no reconhecimento de palavras.

\subsection{Palavras lidas por minuto: Fluência x Proficiência}

Alguns estudos sobre língua materna e segunda língua têm proposto que a fluência na leitura pode ser definida a partir de critérios como, a precisão de palavras lidas, tempo de leitura e prosódia durante a leitura. Logo, para que seja possível investigar a relação entre leitura e medidas de leitura oral, coeficientes de medidas deveriam ser estabelecidos, calculados, analisados e descritos.

Desse modo, ao presente estudo interessa considerar o tempo de leitura enquanto coeficiente válido, não apenas para ilustrar a automaticidade de reconhecimento de palavras e compreensão leitora, mas, principalmente, enquanto reflexo de uma leitura fluente e proficiente. Assim, a discussão que ora empreendemos, assume a validade do referido fator, uma vez que consideramos existir uma relação entre a fluência de leitura, o tempo de leitura em tarefas 
específicas e o nível de proficiência de um falante/leitor.

Segundo Tavakoli (2011), no que diz respeito à comunidade de ensino de segunda língua, o termo fluência tem sido usado alternadamente em relação ao termo de proficiência oral geral. Em um sentido amplo, a fluência também poderia ser chamada de proficiência oral global, isto porque, segundo o autor, em se tratando de fluência em segunda língua, nós frequentemente a pensamos como proficiência.

Segalowitz (2010) propõe que diferentes autores têm definido fluência diferentemente, em algumas línguas, inclusive, a equivalência exata para o termo fluência seria inexistente. Segundo o autor, as qualidades que tornariam um discurso fluente seriam, rápido tempo de leitura, relativa ausência de hesitações, pausas, repetições e reparos. Nesse sentido, nas palavras do autor, uma fala ou discurso fluente resultaria de um discurso preciso, apropriado e natural em termos de convenções de uso da língua.

Segundo Anema (2008, p.66), o ritmo de leitura pode ser calculado a partir das palavras corretas lidas por minuto (PCLM). As palavras corretas lidas por minuto seriam, assim, calculadas a partir do número de palavras lidas corretamente em uma passagem por um dado indivíduo e dividida pelo tempo total de leitura em segundos. Assim, erros como repetição de palavras, adição de palavras, omissões de palavras e palavras mal interpretadas, mal lidas ou disfluências, contabilizariam palavras incorretas, resultando, obrigatoriamente, na subtração no número total de palavras lidas, mediante as palavras consideradas como lidas corretamente.

Segalowitz (2010, p.47) sugere fluência enquanto traços do desempenho oral na segunda língua de um falante que sirva de indicador confiável e seguro de como eficientemente esse falante está apto a mobilizar e temporariamente integrar, de um modo relativamente simultâneo, o processo subjacente de planejar e construir enunciados a fim de desempenhar um discurso ou fala comunicavelmente aceitável.

Assim, nos termos de Tavakoli (2011), se fluência também pode, em alguma extensão, ser chamada ou assumida como proficiência oral global, e por assim sê-la, julgamos relevante considerar o número de palavras lidas por minuto, em decorrência de ausências de hesitações pausas, omissões, repetições e disfluências mediante as palavras lidas, não apenas como um coeficiente de fluência de leitura na L2, mas, sobretudo, como um indicador de provável proficiência nessa língua, em face da descrição e caracterização do perfil de seus falantes.

\section{Aspectos Metodológicos e Experimentais}

O experimento descrito neste artigo contou com 166 participantes, dos quais 73 eram do sexo masculino e 93 do sexo feminino, recrutados em Nova Iorque - Estados Unidos (Queens College - CUNY) e João Pessoa - Brasil (Universidade Federal da Paraíba). Os participantes apresentavam faixa etária entre os 18 e 50 anos.

Os sujeitos recrutados realizaram um teste oral de leitura com cento e nove (109) palavras, cujo objetivo era medir o tempo de leitura, número de palavras lidas por minuto, número de palavras corretas lidas e número de erros (imprecisões) cometidos durante a tarefa realizada (ANEMA, 2008).

A cronometragem do tempo de leitura deu-se através do aplicativo Be Focused Pro - Focus Timer instalado em um Macbook Air - Apple e fora realizada pelo investigador principal deste estudo.

A leitura do texto, cuja temática versava sobre Nova Iorque e seus principais codinomes, era seguida por duas questões de compreensão textual, de modo não apenas a assegurar a atenção de cada sujeito testado, mas, sobretudo, para que nos fosse legitimada a evidência que o participante era capaz de entender e interpretar o texto em questão, conforme é possível observar no quadro 01. 


\section{New York City}

New York is the most populous city in the United States and the center of the New York metropolitan area. New York City is the premier gateway for immigration into the United States and it is one of the most populous urban agglomerations in the world. The city is referred to as New York City or the City of New York to distinguish it from the State of New York, of which it is a part. It has also been called by many nicknames such as the "City that Never Sleeps" and the "Center of the

Universe." But the Big Apple is the most famous nickname.

1. "New York" refers to just one place.
A) True
B) False

2. The "Center of the Universe" is the most famous nickname of New York City.
A)!True!
B) False

Quadro 01. Tarefa de Leitura e Compreensão Textuais

Os sujeitos então eram orientados sobre a tarefa, seguido de três minutos para realizarem uma leitura silenciosa do texto para que pudessem se familiarizar com as palavras que eventualmente lhes fossem desconhecidas.

Uma vez que a leitura tivesse sido iniciada, as pausas durante a leitura, as adições de palavras, as hesitações e os falsos inícios, seriam considerados como erros ou inadequações. Após a leitura do texto, cada sujeito deveria acertar pelo menos uma das questões referentes à compreensão textual, para que sua tarefa fosse considerada válida. Todos os sujeitos, que se submeteram à leitura do texto, acertaram predominantemente as duas questões.

Para os sujeitos recrutados no exterior atribuímos a classificação de nativos monolíngues àqueles que tinham nascido nos Estados Unidos e, eventualmente não falassem, ou sequer tivessem estudado, alguma outra língua além do inglês, em contexto formal de ensino; já aos participantes que tinham nascido nos Estados Unidos, mas que falassem além do inglês uma outra língua, ambas desde a infância, atribuímos a classificação de bilíngues nativos. Salientamos que a literatura tem exaustivamente classificado esse tipo de bilíngue como bilíngues de nascença (ou early bilinguals) (cf. BEARDSMORE, 1986; SWAIN, 1972). Por fim, classificamos como bilíngues tardios aqueles participantes que tivessem estudado ou adquirido a língua-alvo após a primeira infância, ou seja, na adolescência ou na vida adulta (cf. BEARDSMORE, 1986; SWAIN, 1972).

No caso deste último grupo de sujeitos, convém a ressalva de que, a maioria deles tinha aprendido ou frequentado escolas bilíngues a partir dos oito anos de idade e viviam em seus países de origem, falando predominantemente sua língua materna. Ao se mudarem para os Estados Unidos, lugar onde ocorreu a primeira fase de aplicação do teste de leitura do presente estudo, 
houve o que os estudos bilíngues denominam de inversão de dominância (GROSJEAN, 2013). Importa-nos ainda mencionar que todos os bilíngues tardios que participaram dos experimentos realizados em Nova Iorque, Estados Unidos, residiam na cidade há, no mínimo, cinco anos, quando da data do experimento.

Diante desse panorama, esclarecemos que, o nosso maior objetivo, ao propor o teste oral de leitura e compreensão, aos sujeitos recrutados no exterior, consistia em aferir o conhecimento explícito deles sobre a língua-alvo e seus potenciais níveis de proficiência. Convém salientar que os sujeitos considerados bilíngues tardios ou imigrantes, pelo presente estudo, eram universitários regularmente matriculados em cursos diversos na Queens College - CUNY, instituição onde o estudo fora realizado.

A mesma tarefa de leitura e compreensão foi reproduzida, realizada, com o grupo de sujeitos recrutados no Brasil, quando da segunda etapa do estudo. Os sujeitos recrutados no Brasil foram igualmente submetidos a todos os procedimentos descritos e que foram realizados com os sujeitos recrutados no exterior, porém, com esses sujeitos, diferentemente daqueles, propusemos um teste de proficiência em língua inglesa chamado VLT (Vocabulary Level Test). Esse teste de proficiência é baseado no nível de vocabulário e quantidade de léxico conhecido por um dado falante de língua (NATION, 1990).

Estudos que têm recorrido e empregado o VLT como teste de proficiência (SOUZA e SOARES-SILVA, 2015), têm atribuído a seguinte classificação, a partir do desempenho demonstrado pelos sujeitos no referido teste: nível avançado aos sujeitos que completam o nível de dez mil palavras $(10,000)$; nível intermediário aos que completam o nível de cinco mil palavras $(5,000)$ e, por fim, nível básico, àqueles que atingem o nível de três mil palavras $(3,000)$.

Assim, os sujeitos recrutados no Brasil foram classificados, inicialmente, a partir do desempenho demonstrado no teste de proficiência (VLT). Todos os sujeitos recrutados no Brasil foram chamados de bilíngues, nos termos de Grosjean (2008), e foram agrupados nos níveis básico, intermediário e avançado considerando os níveis de palavras atingidos durante o teste de proficiência mencionado (NATION, 1990).

Desse modo, atribuímos a seguinte classificação aos sujeitos bilíngues brasileiros: bilíngues brasileiros - nível avançado aos sujeitos que completaram o nível de dez mil palavras $(10,000)$; bilíngues brasileiros - nível intermediário aos que completaram o nível de cinco mil palavras $(5,000)$ e, por fim, bilíngues brasileiros - nível básico, àqueles que atingiram o nível de três mil palavras $(3,000)$.

Os sujeitos recrutados no Brasil eram todos falantes de português brasileiro como língua materna, considerados falantes de língua inglesa como segunda língua, alunos regularmente matriculados nos cursos de graduação da Universidade Federal da Paraíba, além de alguns professores de graduação do curso de Letras-Inglês da mesma instituição de ensino, João Pessoa Brasil, com idade entre 18 e 50 anos.

\subsection{Perfil de Lingua e Sujeitos: Monolingues, Bilingues e Bilinguismos}

Ao considerarmos que o bilinguismo seja a norma e não a excessão em muitos países por motivos diversos, como os sugeridos por Bialystok et al (2009) e sobretudo que os clássicos falantes monolíngues não devam ser utilizados, única e exclusivamente, como termo comparativo em estudos envolvendo falantes bilíngues, conforme recomendado por Sorace (2011), dedicamos a presente seção para descrever quantitativa e qualitativamente os sujeitos participantes do experimento proposto, de modo a oferecer informações adicionais válidas sobre o contexto de língua o qual encontravam-se inseridos, de modo a nos ser possível, não apenas a caracterização dos bilinguismos de cada um dos grupos de sujeitos bilíngues e sua proficiência, mas também, da caracterização dos participantes monolíngues. 
Os sujeitos recrutados no exterior (Nova Iorque, Estados Unidos) foram classificados como nativos monolíngues (NM), nativos bilíngues (NB) e bilíngues tardios (BT); e os sujeitos recrutados no Brasil (João Pessoa, Paraíba) foram classificados como bilíngues brasileiros - nível avançado (BBNA), bilíngues brasileiros - nível intermediário (BBNI) e bilíngues brasileiros - nível básico (BBNB). A organização entre a relação dos grupos de sujeitos e o sexo dos integrantes de cada um deles pode ser observada no gráfico 01.

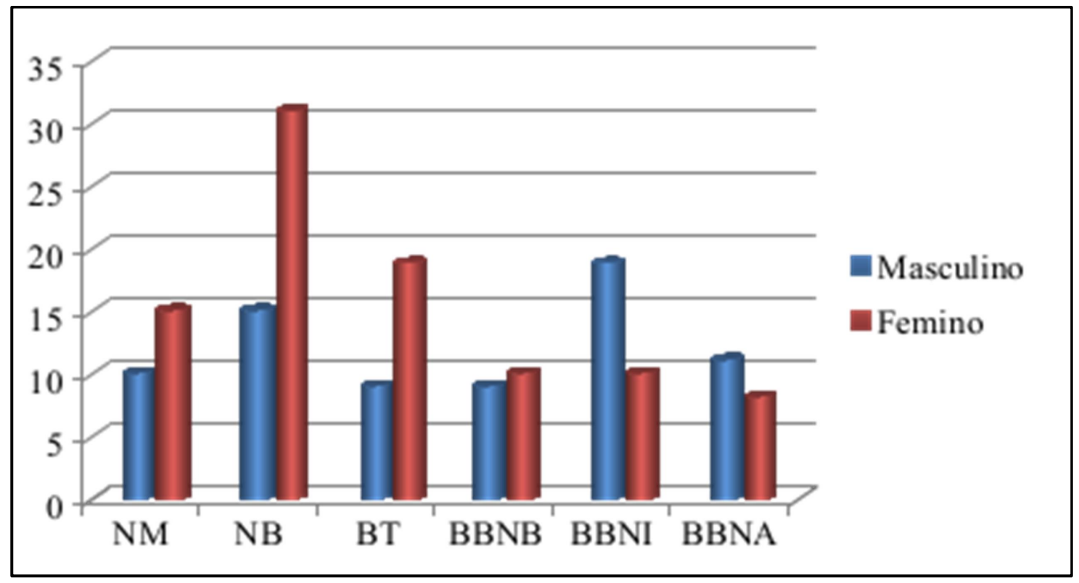

Gráfico 01. Sexo dos participantes recrutados

Embora os sujeitos do exterior tenham sido recrutados nos Estados Unidos - Nova Iorque, alguns participantes apresentavam país de origem distinto aquele onde residiam quando do momento da realização deste experimento. Em relação aos sujeitos que foram recrutados em João Pessoa - Brasil, todos atestaram como país de origem o Brasil.

Em se tratando do país de origem dos participantes e a possível influência de tal fator como relevante na exposição à língua-alvo ou até mesmo de uma eventual caracterização do perfil de língua e do bilinguismo, organizamos os grupos de sujeitos recrutados e seus respectivos países de origem no gráfico 02 .

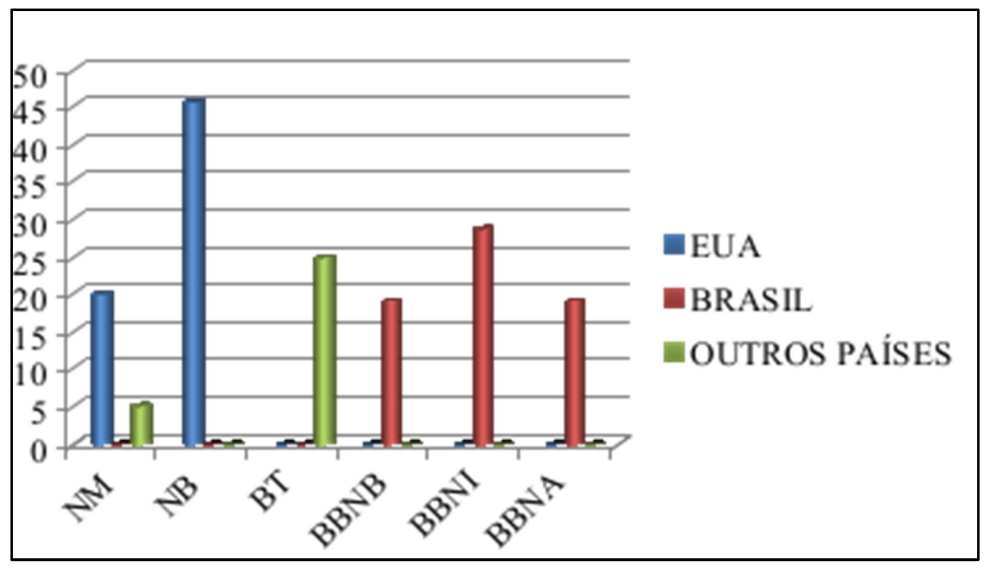

Gráfico 02. País de origem dos participantes

Conforme observado no gráfico acima, o grupo mais heterogêneo de sujeitos, em relação ao país de origem, é o grupo de bilíngues tardios, os quais viveram grande parte de suas vidas em seus países de origem (Índia, Rússia, Coreia, Japão, República Dominicana, Colômbia, Alemanha e Grécia) e, após a adolescência, mudaram para os Estados Unidos. Tal realidade não apenas apresenta reflexos reais e fundamentais em virtude do processo de aquisição e aprendizagem da língua recipiente para esse grupo de sujeitos, mas pode influenciar diretamente na proficiência e, eventualmente, na dominância de suas línguas (cf. GROSJEAN, 2008). 
Em se tratando das línguas maternas de seus pais (pai e mãe),de modo a nos permitir saber em quais outras línguas seus país pudessem interagir com eles, a considerar que o bilinguismo diz respeito a diversas possibilidades de uso de ambas ou uma das línguas do bilíngues, pudemos observar, conforme ilustrado no gráfico 03, a seguinte relação entre as línguas faladas pelos pais dos sujeitos recrutados e o perfil de bilinguismo de cada um deles.

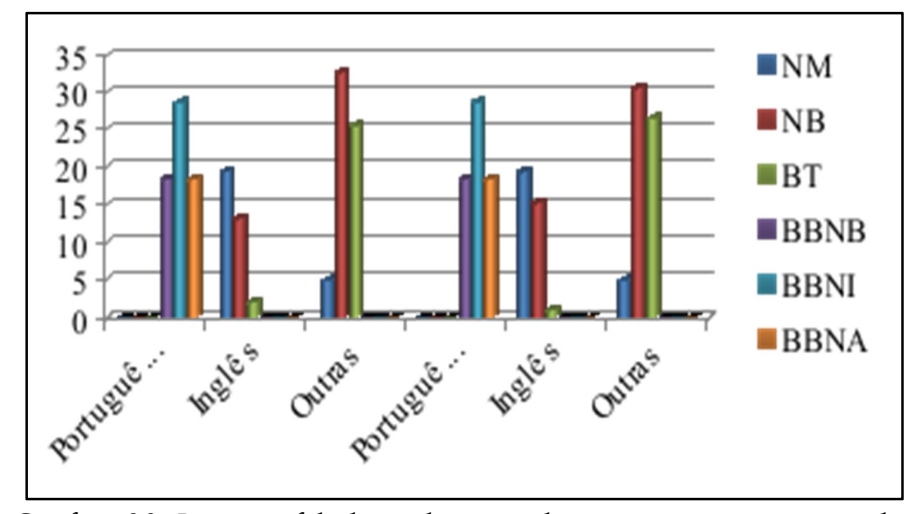

Gráfico 03. Línguas faladas pelos pais dos participantes recrutados

Ainda que sendo submetidos a testes que visavam mensurar sua proficiência na língua recipiente, a exemplo do teste de leitura oral em questão e o VLT (Vocabulary Level Test), pedimos que os participantes avaliassem seu nível de proficiência na língua-alvo, sobretudo porque, conforme sugere a literatura, bilíngues não seriam bons informantes de sua própria proficiência (cf. Grosjean, 2008).

Nesse sentido, no gráfico 04, é possível observar os grupos de sujeitos mencionados a partir da proficiência que informaram ter na L2.

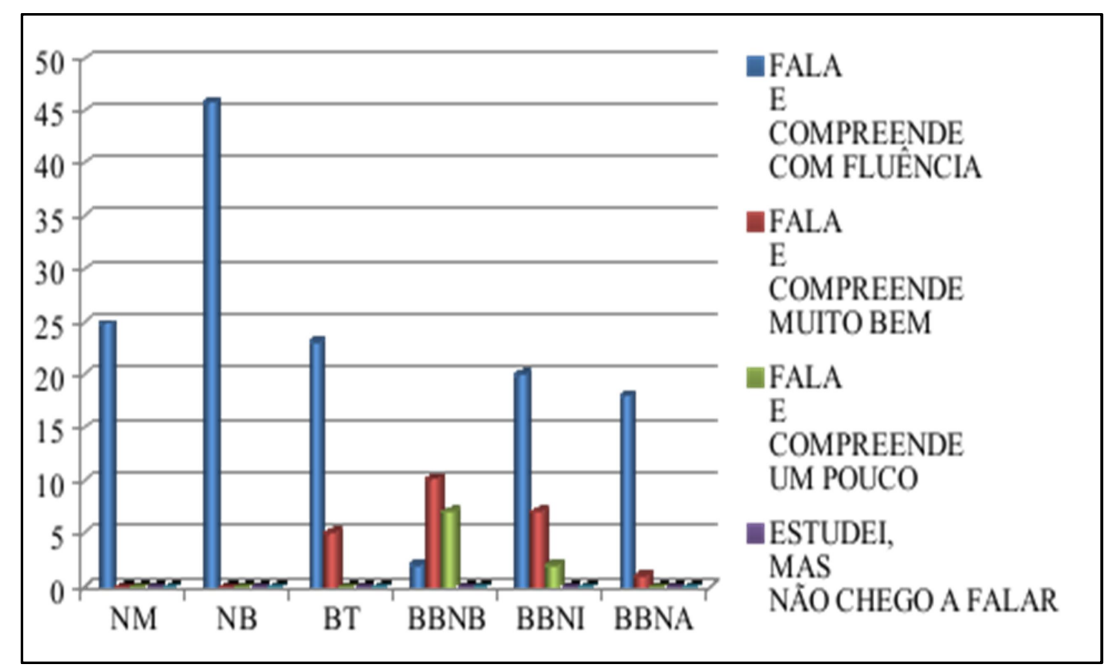

Gráfico 04. Habilidades na língua-alvo informadas pelo participantes recrutados

É importante notar no gráfico acima que não apenas os monolíngues nativos, geralmente assumidos como termo comparativo em estudos sobre o bilinguismo (SORACE, 2011), mas também os demais grupos de bilíngues, inclusive os de bilíngues tardios e bilíngues brasileiros níveis intermediário e avançado atestaram falar e compreender com fluência a língua inglesa. Os bilíngues brasileiros - nível básico, timidamente, atestam majoritariamente falarem e compreenderem bem, ou falarem e compreenderem pouco. Ainda assim, alguns participantes desses grupo alegaram falar e compreender com fluência.

Ainda em se tratando das habilidades na língua-alvo, procuramos ilustrar no gráfico 05, as informações obtidas, necessariamente, com o grupo de bilíngues brasileiros, sobre experiências de 
moradia no exterior enquanto fator relevante junto ao desenvolvimento de proficiência em L2 (COLEMAN, 1997 e CUMMINS, 2009). Não incluímos as respostas dos participantes recrutados nos Estados Unidos, no caso dos nativos monolíngues e bilíngues tardios, por terem-no como país de residência desde o nascimento e não terem sido reportados casos relevantes de residência fora do país que excedesse três meses. No caso dos bilíngues tardios, essa "viagem/moradia" tinha há muito se prolongado, considerando que o país de destino havia se tornado país de residência há no mínimo três anos.

Assim, objetivando ilustrar as experiências de bilíngues brasileiros em face das viagens realizadas e tempo de residência no exterior em países cuja língua majoritária do país de origem fosse o inglês, propusemos o gráfico 05.

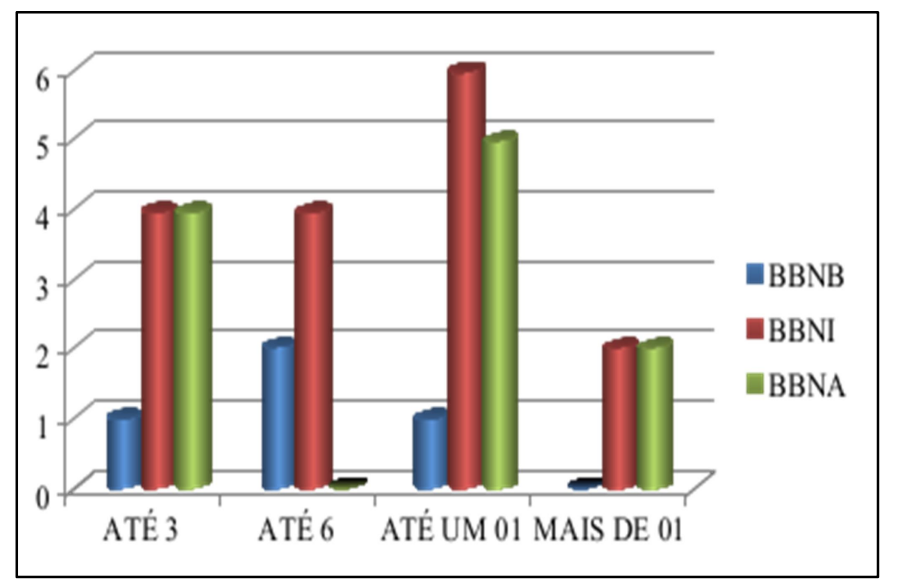

Gráfico 05. Tempo de residência no exterior dos participantes recrutados no Brasil

Podemos perceber que os bilíngues brasileiros que apresentaram maior tempo de residência no exterior em países como os Estados Unidos, Inglaterra, Austrália e Irlanda (informação indicada pelos próprios sujeitos), pertencem ao nível de proficiência avançado e intermediário. Poucos foram os bilíngues brasileiros - nível básico que chegaram a residir entre um ou mais de um ano no exterior.

Por fim e, para o presente estudo, consideramos relevante o idioma majoritário de instrução no qual os participantes receberam instrução ao longo de sua educação formal (LONG, 1983; KRASHEN, 1988 e ELLIS, 2014). A respeito do histórico de escolaridade dos participantes e das diversas possibilidades linguísticas envolvidas desde a educação no nível básico ao ensino superior, propusemos o gráfico 06.

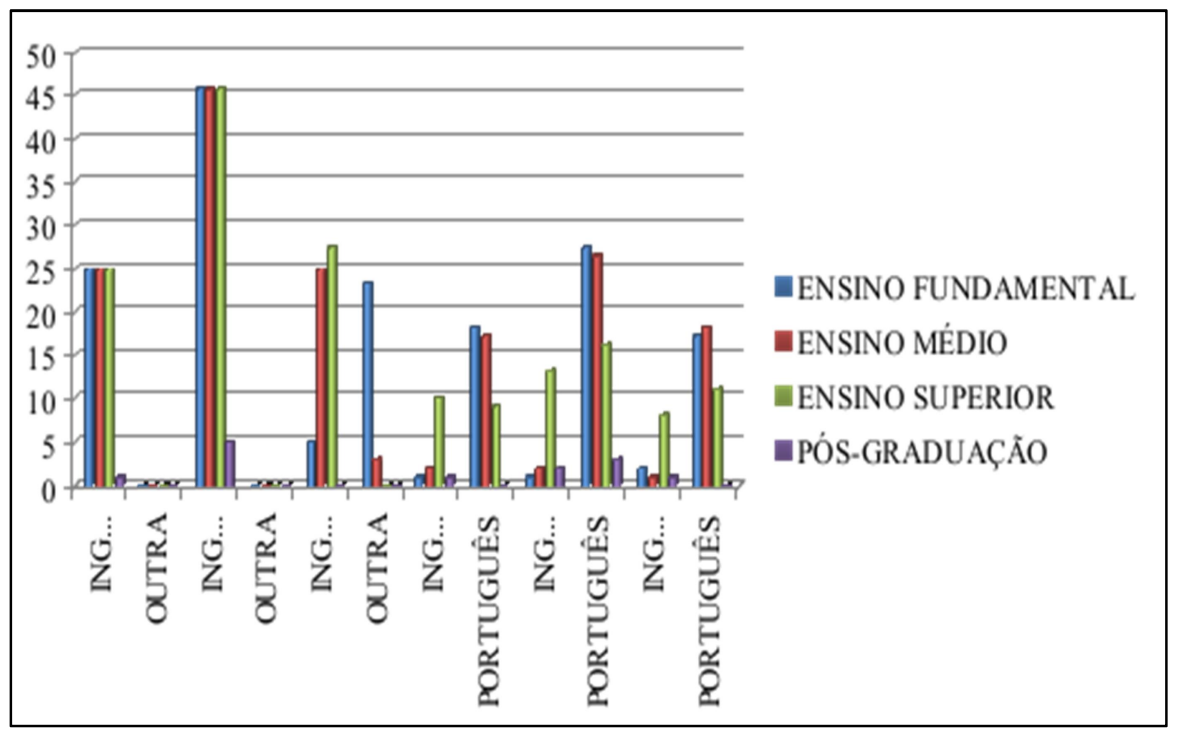


Gráfico 06. Histórico de escolaridade e língua de instrução dos participantes recrutados

Exceto os nativos monolíngues e bilíngues nativos que receberam instrução ao longo de toda sua educação formal básica e superior em língua inglesa e, os bilíngues tardios que, ainda quando em seus países de origem receberam instrução bilíngue (sua língua materna e língua inglesa), antes de mudarem para os Estados Unidos, onde recebem instrução formal no nível superior exclusivamente em inglês, temos poucos casos de formação escolar bilíngue no Brasil (portuguêsinglês) entre os sujeitos investigados, cuja formação em língua inglesa, ocorre (eu) no ensino superior. Isso porque, parte dos participantes são (foram) graduandos do curso Letras-Inglês ou alunos de cursos outros com experiência acadêmica no exterior devido ao programa $\operatorname{CSF}^{32}$, atual ISF.

Após a descrição dos aspectos metodológicos, configuração do experimento empreendido e perfil dos sujeitos recrutados no Brasil e no exterior, os quais foram classificados e agrupados conforme proficiência e contexto de bilinguismo no qual estavam inseridos, estamos certos da validade e relevância dos dados obtidos, os quais são apresentados na seção de análise e discussão de dados que se segue.

\section{Teste Oral de Leitura e Compreensão de Texto: Análise de Dados}

Os sujeitos investigados (166), após realização do teste VLT (Vocabulary Level Test NATION, 1990) e da tarefa de leitura e compreensão de texto foram assim agrupados: vinte e cinco (25) sujeitos foram considerados monolíngues nativos; quarenta e seis (46) bilíngues nativos (bilíngues de nascença); vinte e oito (28) bilíngues tardios, dezenove (19) bilíngues brasileiros nível avançado; vinte e nove (29) bilíngues brasileiros - nível intermediário e, por fim, dezenove (19) bilíngues brasileiros - nível básico.

A classificação mencionada visa a auxiliar a compreensão do leitor dos gráficos propostos na descrição dos dados obtidos.

A análise que propomos a seguir busca, portanto, validar a classificação dos "bilinguismos" e nível proficiência dos sujeitos bilíngues brasileiros, em comparação aos sujeitos bilíngues investigados nos Estados Unidos, a partir do cruzamento e contraste dos dados obtidos pelo VLT (Vocabulary Level Test) e pela tarefa de leitura oral.

Assim sendo, a análise que se segue, visa a estabelecer correlações entre o número de palavras lidas, tempo de leitura destinado ao texto lido, número de palavras corretas lidas e erros referentes ao teste oral, com o nível de proficiência na língua-alvo comumente aferido pelo teste mencionado.

As diferenças observadas, nas categorias sob análise, entre o desempenho dos grupos de sujeitos, bem como os padrões observados, deu-se em virtude da Análise Multivariada (MANOVA) e são apresentados no Gráfico 07.

No que diz respeito às médias de cada uma das categorias analisadas para cada um dos grupos investigados, foi observada significância entre as médias obtidas, MANOVA $(f(1,166)=$ $7,17 ; \mathrm{p}<.0,5)$. Sobre as médias do tempo de leitura para cada grupo, foi percebida diferença significativa, MANOVA $(\mathrm{f}(1,166)=12,57 ; \mathrm{p}<.0,5)$, a partir da qual foi observado que a média, em segundos, do tempo de leitura dos nativos monolíngues durante a realização da leitura do texto foi de 32,69s; a dos nativos bilíngues foi de 33s, a dos bilíngues tardios foi de 35,89s, a dos bilíngues brasileiros - nível avançado, em contrapartida, foi de 35,33s, a dos bilíngues brasileiros - nível

\footnotetext{
32 O Programa Ciências sem Fronteiras, conhecido também pela sigla CSF (posteriormente, Idiomas sem Fronteiras), foi uma iniciativa do Ministério da Educação que tinha por objetivo aprimorar o conhecimento em inglês (bem como outros idiomas) dos estudantes universitários brasileiros. A ideia central do programa era propiciar uma mudança no ensino de idiomas estrangeiros nas universidades do país.
} 
intermediário foi de 39,96 s e por fim, a média do tempo de leitura dos bilíngues brasileiros - nível básico, que foi de 43,57s, conforme é possível observar no Gráfico 01.

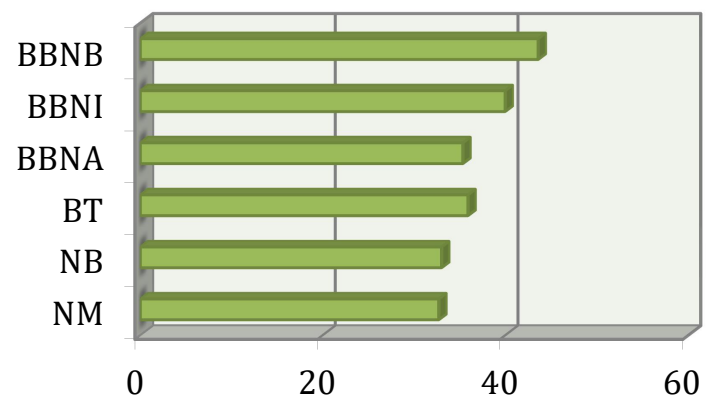

Gráfico 07. Teste Oral: Média do Tempo de Leitura

No entanto, a diferença das médias entre os grupos, calculada a partir do Teste de Tukey, Test de Tukey $(f(1,166)=12,57 ; p<.0,5)$, só foi significativa, mediante a comparação entre os grupos de:

a. Nativos monolíngues e bilíngues brasileiros - nível básico ( $\mathrm{p}<.0,5)$, em que a diferença observada foi de 10,88 segundos;

b. Nativos monolíngues e bilíngues brasileiros - nível intermediário $(p<0,0002)$, cuja diferença foi de 7,27 segundos;

c. Nativos bilíngues e bilíngues brasileiros - nível básico $(\mathrm{p}<.0,5)$, sendo observada a diferença de 10,57 segundos;

d. Nativos bilíngues e bilíngues brasileiros - nível intermediário ( $\mathrm{p}<.0,5)$, sendo de 6,96 segundos a diferença observada;

e. Bilíngues tardios e bilíngues brasileiros - nível básico ( $\mathrm{p}<0,0003)$, em que foi percebida a diferença de 7,68 segundos de diferença;

f. Por fim, temos a comparação das médias do tempo de leitura entre os bilíngues brasileiros - nível avançado e os bilíngues brasileiros - nível básico ( $\mathrm{p}<.0,5)$, cuja diferença observada foi de 8,24 segundos.

Em se tratando das médias de cada grupo para a variável palavras corretas lidas durante a tarefa, MANOVA $(f(1,166)=4,56 ; p<0,0006)$, foi observado que a média de palavras lidas pelos nativos monolíngues foi de 105 palavras; a dos bilíngues nativos também foi 105 palavras; a dos bilíngues tardios, por sua vez, foi de 104 palavras corretas; a média dos bilíngues brasileiros - nível avançado foi de 106 palavras; em relação ao bilíngues brasileiros - nível intermediário cuja média foi de 104 palavras; por fim, a média de palavras corretas lidas pelos bilíngues brasileiros - nível básico foi de 95 palavras, segundo ilustrado no Gráfico 08 .

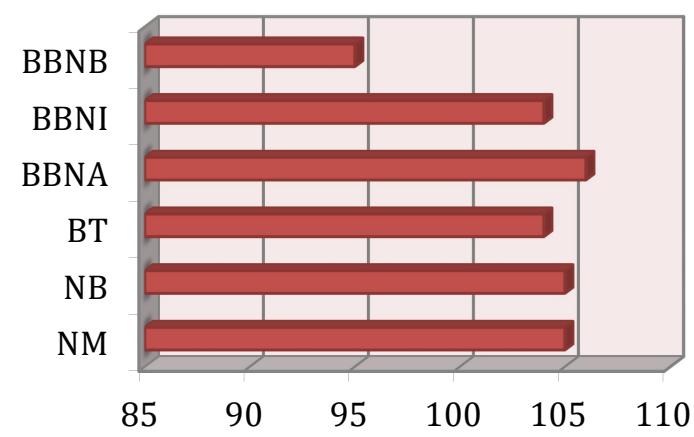

Gráfico 08. Teste Oral: Média de Palavras Corretas Lidas 
Todavia, a diferença observada durante a comparação entre as médias de palavras corretas lidas durante o teste de leitura, Teste de Tukey $(f(1,166)=4,56 ; p<0,0006)$, só foi significativa entre os grupos de:

a. Nativos monolíngues e bilíngues brasileiros - nível básico $(\mathrm{p}<0,003)$, cuja diferença observada foi de 10 palavras;

b. Nativos bilíngues e bilíngues brasileiros - nível básico $(\mathrm{p}<0,0005)$, sendo também de 10 palavras a diferença observada;

c. Bilíngues tardios e bilíngues brasileiros - nível básico $(\mathrm{p}<0,008)$, em que foi observada a diferença de 09 palavras;

d. Bilíngues brasileiros - nível avançado e bilíngues brasileiros - nível básico, $(\mathrm{p}<0,0002)$, em que a diferença foi de 11 palavras;

e. Por último, temos os bilíngues brasileiros - nível intermediário e bilíngues brasileiros nível básico $(p<0,005)$, cuja comparação das médias das palavras corretas lidas resultou na diferença de 09 palavras.

Em relação às médias obtidas a partir dos erros cometidos durante a leitura do texto, para cada um dos grupos de sujeitos, MANOVA $(f(1,166)=11,44 ; p<0,0006)$, percebemos que a média do número de erros cometidos pelos nativos monolíngues foi de 02; a dos bilíngues nativos também foi de 02; a média do número de erros cometidos pelo bilíngues tardios foi de 03; a dos bilíngues brasileiros - nível avançado foi de 02; a média dos bilíngues brasileiros - nível intermediário foi de 04; e a dos bilíngues brasileiros - nível básico foi de 04 . A média do número de erros cometidos durante a leitura do teste oral para cada um dos grupos pode ser observada no Gráfico 09.

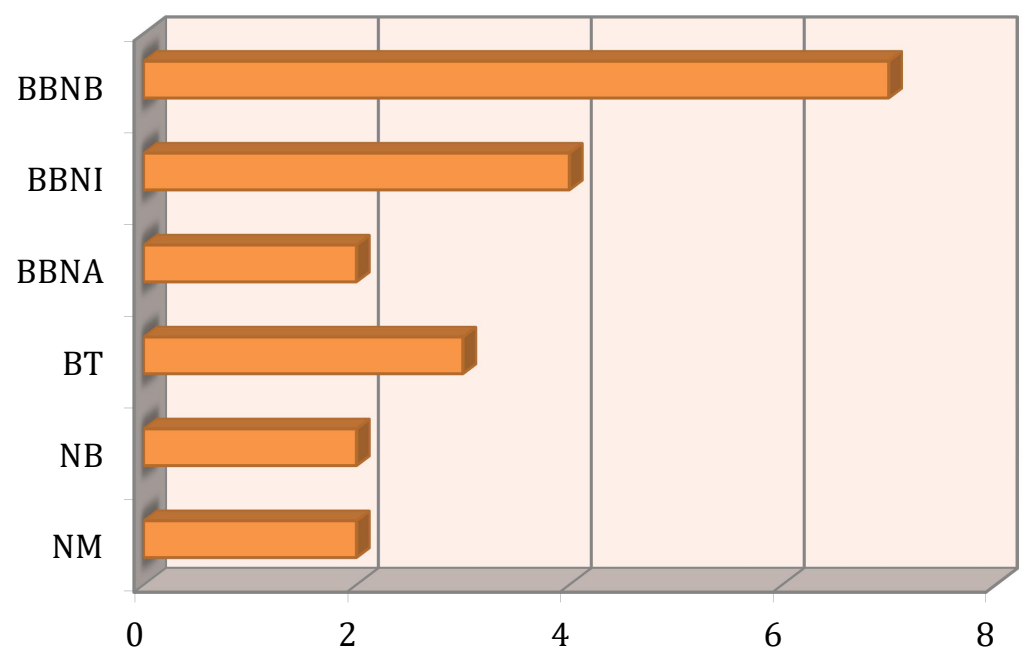

Gráfico 09. Teste Oral: Média de Erros

Entretanto, a diferença entre as médias dos erros cometidos durante o texto, Teste de Tukey $(f(1,166)=11,44 ; p<.0,5)$, só foi significativa entre os grupos de:

a. Nativos monolíngues e bilíngues brasileiros - nível básico ( $\mathrm{p}<.0,5)$, em que foi observada a diferença de 05 erros;

b. Nativos bilíngues e bilíngues brasileiros - nível básico $(p<0.5)$, cuja diferença foi também de 05 erros; 
c. Nativos bilíngues e bilíngues brasileiros - nível intermediário $(\mathrm{p}<0,05)$, sendo a diferença observada foi de 02 erros;

d. Bilíngues tardios e bilíngues brasileiros - nível básico ( $p<.0,5)$, em que foi observada a diferença de 05 erros;

e. Bilíngues brasileiros - nível avançado e bilíngues brasileiros - nível básico ( $<<.0,5)$, em que a diferença foi de 05 erros;

f. Por fim, temos a comparação das médias do erros cometidos durante o teste oral entre os bilíngues brasileiros - nível intermediário e os bilíngues brasileiros - nível básico ( $p<.0,5)$, em que foi observada a diferença de 03 erros.

Sobre as médias das palavras lidas por minuto referentes a cada um dos grupos de sujeitos sob análise, MANOVA $(\mathrm{f}(1,166)=24,47 ; \mathrm{p}<.0,5)$, temos, finalmente, a dizer que a média de palavras lidas por minuto durante o teste oral por parte dos nativos monolíngues foi de 195 palavras; a dos bilíngues nativos foi de 192 palavras, a média de palavras lidas por minuto dos bilíngues tardios foi de 176 palavras, a dos bilíngues brasileiros - nível avançado foi de 182 palavras, a dos bilíngues brasileiros - nível intermediário foi de 158 palavras e, por último, temos a média dos bilíngues brasileiros - nível básico que foi de 127 palavras. O Gráfico 10 apresenta as médias de palavras lidas por minuto por cada um dos grupos de sujeitos mencionado.

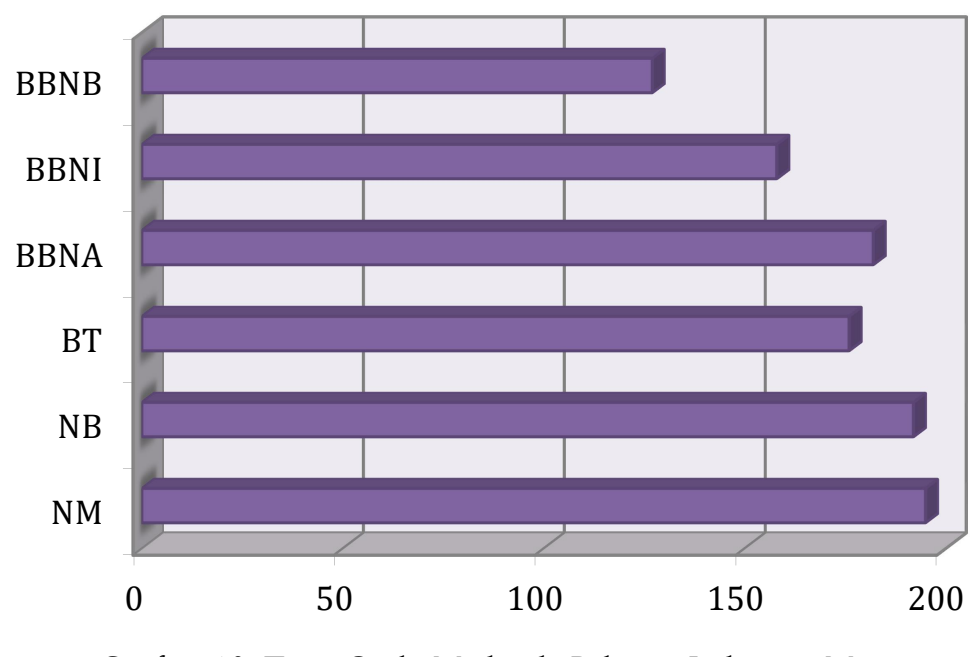

Gráfico 10. Teste Oral: Média de Palavras Lidas por Minuto

Porém, a diferença entre as médias das palavras lidas por minutos obtidas a partir da realização do teste oral, Teste de Tukey $(\mathrm{f}(1,166)=11,44 ; \mathrm{p}<.0,5)$, só foi significativa entre os grupos de:

a. Nativos monolíngues e bilíngues brasileiros - nível intermediário ( $p<.0,5)$; cuja diferença foi de 37 palavras;

b. Nativos monolíngues e bilíngues brasileiros - nível básico $(\mathrm{p}<.0,5)$; sendo de 68 palavras a diferença observada;

c. Nativos bilíngues e bilíngues brasileiros - nível intermediário $(\mathrm{p}<.0,5)$; em que a diferença foi de 34 palavras;

d. Nativos bilíngues e bilíngues brasileiros - nível básico $(\mathrm{p}<.0,5)$; cuja diferença observada foi de 65 palavras;

e. Bilíngues tardios e bilíngues brasileiros - nível básico $(p<.0,5)$; em que foi observada a diferença de 49 palavras; 
f. Bilíngues brasileiros - nível avançado e bilíngues brasileiros - nível intermediário ( $\mathrm{p}<0,01)$; sendo observada a diferença de 24 palavras;

g. Bilíngues brasileiros - nível avançado e bilíngues brasileiros nível básico ( $\mathrm{p}<.0,5)$; cuja diferença observada foi de 55 palavras;

h. E, por fim, a comparação entre as médias das palavras lidas por minuto entre os bilíngues brasileiros - nível intermediário e os bilíngues brasileiros - nível básico ( $p<0,0006)$; em que a diferença foi de 31 palavras.

Após análise e descrição dos dados obtidos a partir do presente estudo, julgamos serem possíveis e legítimas algumas suposições. Isto porque, a partir dos dados acima descritos e, sobretudo, por considerarmos a ausência de diferenças significativas entre as variáveis elencadas no teste de leitura oral entre nativos monolíngues, bilíngues nativos e bilíngues brasileiros - nível avançado e a considerável semelhança dos resultados obtidos por meio das variáveis propostas, durante a análise do teste oral, poderíamos sugerir que todos esses grupos de sujeitos poderiam ser considerados falantes avançados de língua inglesa. Principalmente se nos basearmos no fato de que os bilíngues brasileiros - nível avançado, receberam essa classificação pelo desempenho aferido no VLT, e o desempenho dos nativos monolíngues e bilíngues nativos terem superado o dos bilíngues brasileiros - nível avançado, no teste oral.

Também, ao percebermos a ausência de diferenças significativas observadas entre os bilíngues tardios e os bilíngues brasileiros - nível intermediário, seria lícito assumir que ambos os grupos disporiam de proficiência intermediária na língua-alvo. Se igualmente nos basearmos no fato de que os bilíngues brasileiros - nível intermediário, assim foram classificados em virtude do desempenho observado a partir do VLT, e o desempenho dos bilíngues tardios supera o dos bilíngues brasileiros - nível avançado, mas não o dos nativos monolíngues, bilíngues nativos e bilíngues brasileiros - nível avançado, no teste oral, poderíamos assumir que os bilíngues tardios seriam considerados falantes intermediários de língua inglesa.

Por fim, teríamos o grupo de bilíngues brasileiros - nível básico, grupo de participantes sujeito às maiores diferenças entre as variáveis elencadas, quando comparados a todos os demais grupos de sujeitos mencionados, e cujo desempenho no teste de leitura oral foi inferior aos demais grupos, portanto, falantes de proficiência básica da língua inglesa.

Assim, por sabermos que estudos têm sido conduzidos objetivando reunir dados relevantes e evidências robustas capazes de corroborar com a premissa de que a quantidade de palavras lidas, tempo total de leitura de tarefa, número de erros e de palavras lidas corretamente, possam ser considerados enquanto potenciais coeficientes indicadores de proficiência (cf. ANEMA, 2008), cabe-nos, a partir deste estudo, refletir acerca, além de aventar sobre a possibilidade de recorrer a tais medidas, enquanto medidas válidas alternativas, para aferir proficiência linguística.

\section{Considerações Finais}

A partir dos dados obtidos através deste estudo, o qual assume a visão holística e aditiva de bilinguismo (GROSJEAN, 2008), a qual propõe que os sistemas linguísticos presentes na mente de um bilíngue não funcionam separadamente e que um sujeito bilíngue não resulta da soma de dois monolíngues, acreditamos ser possível realizar algumas considerações.

Inicialmente, retomamos a discussão de que sujeitos bilíngues têm sido analisados e descritos a partir de sua proficiência em uma de suas línguas ou até mesmo em ambas, e, que, diferentes métodos e instrumentos de aferição têm sido considerados e utilizados na tentativa de descrever, classificar ou agrupar sujeitos bilíngues em termos subtrativos e perspectivas monolíngues.

No entanto, a partir dos resultados encontrados, sugerimos que pesquisas envolvendo sujeitos bilíngues e sua proficiência em língua inglesa, por exemplo, devam dispor de instrumentos 
que considerem a diversidade linguística e contextual inerente ao próprio fenômeno do bilinguismo.

Assim, a partir do estudo proposto e da análise conduzida, é possível levantar uma discussão sobre a existência e possibilidades outras de atestar ou aferir a proficiência linguística e fluência oral global (SEGALOWITZ, 2010; TAVAKOLI, 2011) de um sujeito bilíngue.

Nesta feita, trazemos à tona a discussão de que embora os nativos monolíngues tenham sido larga e recorrentemente utilizados em estudos sobre o bilinguismo como padrão comparativo, a discussão sobre bilinguismo se torna mais profícua quando os bilíngues e os seus bilinguismos também são incluídos e condiderados como tal.

Por fim, entendemos que dissertar sobre modelos e instrumentos de aferição de proficiência linguística e proficiência oral global de sujeitos bilíngues resultaria muito menos em buscar um modelo geral, ideal ou unilateral de bilinguismo, e muito mais em enxergar os contextos linguísticos e culturais individuais concernentes a cada tipo de realidade bilíngue e falantes bilíngues envolvidos em estudos dessa natureza.

\section{Referências}

ANEMA, I. The Relationship between Fluency-Based Suprasegmentals and Comprehension in Oral and Silent Reading in Dutch Speakers of English. Master Dissertation. The City University of New York. New York City, 2008.

BEARDSMORE, H. B. Bilingualism: basic principles. (Vol. 1). Multilingual Matters, 1986.

BIALYSTOK, E.; CRAIK, F.I.M.; GREEN, D.W.; GOLLAN, T.H. Bilingual Minds. Association for Psychological Science. 10(3) pp.89-129, 2009.

CHEE, M. W. L.; TAN, E. W. L.; THIEL, T. Mandarin and English single word processing studied with functional magnetic resonance imaging. Journal of Neuroscience, 19(8), pp. 3050-3056, 1999.

COOK, V. The poverty-of-the-stimulus argument and multi-competence, Second Language Research, 7, 2, pp. 103-117, 1991.

COOK, V. Evidence for multicompetence, Language Learning 42, pp.557-91, 1992.

COOK, V. The consequences of bilingualism for cognitive processing. In.: GROOT, A.; KROLL, J.F. (eds.), 1997 Tutorials in Bilingualism: Psycholinguistic Perspectives, Lawrence Erlbaum, pp. 279. 300, 1997.

COOK, V. Premises of Multi-competence. IN.: COOK, V.; WEI, L. The Cambridge Handbook of Linguistic Multi-Competence. Cambridge University Press, 2016.

DE DIEGO BALAGUER, R.; SEBASTIÁN-GALLÉS, N.; DÍAZ, B.; RODRÍGUES-FORNELLS, A. Morphological processing in early bilinguals: An ERP study of regular and irregular verb processing. Cognitive Brain Research, 25, pp. 312-327, 2005.

ELLIS, R. Principles of Instructed Second Language Learning. In.: CELCE-MURCIA, M; BRINTON, D. M.; SNOW, M.A. Teaching English as a Second or Foreign Language. $4^{\text {th }}$ edition. Boston, MA: National Geographic Learning, 2014.

GROSJEAN, F. Studying Bilinguals. Oxford: Oxford University Press, 2008.

GROSJEAN, F. Bilingual: Life and Reality. Cambridge, Mass: Harvard University Press, 2010.

GROSJEAN, F. The Psycolinguistics of Bilingualism. Wiley-Blackwell, 2013.

GRABE, W. Current developments in second language reading research. TESOL Quarterly, 25, pp. 375-406, 1991.

HSIN, L. et al. Priming Cross-Linguistic Interference in Spanish-English Bilingual Children. Cascadilla Press, 2013. 
KRASHEN, S.D. Second Language Acquisition and Second Language Learning. Prentice-Hall International, 1988.

LYONS, J. Language and linguistics. Cambridge: Cambridge University Press, 1981.

LONG, M. Does second language instruction make a difference? A review of the research. TESOL Quarterly, 17, pp. 359-382, 1983.

NATION, I.S.P. Teaching and learning vocabulary. New York: Newbury House, 1990.

NEWMAN, A. J.; TREMBLAY, A.; NICHOLS, E. S.; NEVILlE, H. J. \& UlLAMN, M. T. The influence of language proficiency on lexical semantic processing in native and late learners of English. Journal of Cognitive Neuroscience, 24(5), 1205-1223, 2012.

NICHOLS, Emily. The influence of proficiency and age of acquisition on second language processing: An $f$ MRI study of Mandarin-English bilinguals. Dissertação de mestrado. University of Western Ontario. 72 páginas, 2013.

PEAL, E.; LAMBERT, W. E. The relation of bilingualism to intelligence. Psychological Monographs, 76, 1-23, 1962.

PERANI, D., PAULESU, E.; GALLES, N. S.; DUPOUX, E.; DEHAENE, S.; BETTINARDI, V.; CAPPA, S. F.; FAZIO, F.; \& MEHLER, J. The bilingual brain: Proficiency and age of acquisition of the second language. Brain, 121(10), 1841-1852, 1998.

PERANI, D.; ABUTALEBI, J.; PAUlESU, E.; SIMONA, B.; SCIFO, P.; CAPPA, S. F. \& FAZIO, F. The role of age of acquisition and language usage in early, high-proficient bilinguals: An fMRI study during verbal fluency. Human Brain Mapping, 19, 170-182, 2003

SEGALOWITZ, N. Cognitive bases of second language fluency. New York: Routledge, 2010.

SEGALOWITZ, N, HULSTIJN J. Automaticity in bilingualism and second language learning. In: Kroll JF, De Groot AMB, editors. Handbook of bilingualism: Psycholinguistic approaches. New York: Oxford University Press. pp. 371-388, 2005.

SORACE, Antonella. Pinning down the concept of "interface" in bilingualism. Linguistic Approaches to Bilingualism 1:1 (2011), 1-33, 2011.

SOUZA, Ricardo Augusto; OLIVEIRA, Fernando Luiz Pereira. Is knowledge of non-dominant L2 activated by bilinguals using their dominat L1? Insights from an on-line Psycholinguistic study. Organon, Porto Alegre, no 51, julho - dezembro, 2011, p. 103-128, 2011.

SOUZA, Ricardo Augusto et al. Brazilian Portuguese-English bilingualism does not afect metalinguistic awareness of L1 constraints in two argument structure constructions. Ilha do Desterro v. 69, no1, p. 017-031, Florianópolis, jan/abr, 2016.

SOUZA, Ricardo Augusto de; SOARES-SILVA, Jesiel. Exploring the measurement of vocabulary size to differentiate Brazilian Portuguese-English bilinguals' access to grammatical knowledge in the L2. Revista Linguística / Revista do Programa de Pós-Graduação em Linguística da Universidade Federal do Rio de Janeiro. Volume 11, número 1, p. 187-204, 2015.

SWAIN, M. K. Bilingualism as a first language. University of California, 1972.

TAVAKOLI, P. Pausing patterns: Differences between L2 learners and native speakers. ELT Journal , 65(1), 71-79, 2011.

VAN ASSCHE, Eva; WOUTER, Duyck, \& HARTSUIKER, Robert J. Context Effects in Bilingual Sentence Processing: Task Specificity. In.: HEREDIA, R.R; ALTARRIBA, J; CIESLICKA, A. B (eds.). Methods in Bilingual Reading Comprehension Research, The Bilingual Mind and Brain Book Series. Springer Science \& Business Media, New York. pp. 11-31, 2016.

WEINREICH, U. Languages in contact. The Hague: Mouton, 1953.

Recebido em: 29/09/19

Aceito em: 03/11/19 